Зайцев А.В.

\title{
ДЕЛИБЕРАТИВНАЯ ДЕМОКРАТИЯ В КОНТЕКСТЕ ДИАЛОГА ГОСУДАРСТВА И ГРАЖДАНСКОГО ОБЩЕСТВА
}

Аннотация: B статье рассказывается об отличии делиберативной модели демократии от электоральной и либеральной демократии и ее близости к представительной демократии и демократии участия. Рассматривается происхождение кониепта «делиберативная демократия» и его смысловые оттенки. При этом сам автор характеризует делиберативную модель демократии еще и как институционализированный диалог государства и гражданского общества. Приводятся взгляды на делиберативную политику различных авторов, при этом акиент делается на политическую философию С.Бенхабиб, которая делиберативный прочесс увязывает с процедурой легитимации принимаемых решений. В заключение статьи рассматривается проблема актуальности делиберативной демократии для современной России.

Review: The article tells us about the difference between the deliberative model of democracy and electoral or liberal democracies. It is shown that deliberative democracy is rather close to representative democracy and participatory democracy. The author of the article also analyzes the origin and definitions of deliberative democracy. The author himself describes the deliberative model of democracy as institutionalized communication between the state institution and civil society. The article describes other views on and concepts of deliberative policy, especially Seyla Benhabib's political philosophy who related the deliberative process with the procedure of legitimization of decisions made. At the end of the article the author talks about a very important role of deliberative democracy for modern Russia.

Ключевые слова: Политология, диалог, дискурс, делиберативная демократия, государство, гражданское общество, публичная политика, легитимность, власть, институционализация

Keywords: political studies, communication, discourse, deliberative democracy, state institution, civil society, public policy, legitimacy, government, institutionalization.

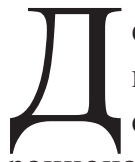

елиберативная демократия -это процедура институционализированного диалога власти и институтов гражданского общества, рационального дискурса, обсуждения, убеждения, аргументации, компромиссов в ее беспартийном варианте. Эта модель демократии основывается на убежденности в том, что человек способен перейти от роли клиента к роли гражданина государства, что он склонен к беспартийности, готов к компромиссу и даже к отказу от своих предпочтений, если они компромиссу мешают.

В отличие от современной демократической практики, где голосование является центральным элементом демократического процесса (электоральная демократия), теоретики делиберативной демократии утверждают, что подлинная легитимность законодательных актов может возникнуть лишь через их предварительное публичное об- суждение. Нами делиберативная демократия рассматривается как публичный диалог (дискурс) институтов государства и граждан, власти и институтов гражданского общества в процессе выработки наиболее приемлемых и оптимальных путей развития То есть, делиберативная демократия сочетает в себе элементы представительной демократии ( representatative democracy), прямой демократии ( direct democracy) и демократии участия ( participatory democracy).

Латинское понятие «deliberatio» пришло в нашу эпоху из словаря римского права и означает «обсуждать», «размышлять», «советоваться», «взвешивать за и против», «проводить консультации». Еще древнеимскому поэту Публию Сиру (I век до н.э.) приписывается правовой «делиберативный» принцип «Deliberandum est diu quod statuendum est semel». Дословно он переводит- 


\section{Политика и общество 10 (106) • 2013}

ся так: «Над тем, что предполагается учредить на очень долгий срок, почти навсегда, положено размышлять так же очень долго». По смыслу к этому высказыванию подходит известная русская поговорка «Семь раз отмерь, один -отрежь», то есть перед тем как совершить какое-либо действие, необходимо размышление о процедуре его осуществлении и возможных последствиях.

В 1774 году в своей знаменитой речи перед избирателями Эдмунд Берк в Бристоле назвал британский парламент совещательным органом (deliberative assembly) нации: «Парламент -не съезд (congress) послов от различных и враждебных держав, интересы которых они обязаны защищать; парламент -это совещательный орган нации с едиными интересами, где руководить должны не местные проблемы и местные предрассудки, а общее благополучие страны, исходящее из общего разума народа». ${ }^{1}$

В современном англо-американском употреблении термин делиберация этимологически основывается на латинском слове deliberare, что означает взвешивать (в идейном смысле), размышлять, совещаться или внимать совету. В английском языке слово делиберация (deliberation) понимается также еще и как обсуждения или дискуссии. Делиберация - это «акт размышлений, взвешивания и изучения причин за и против выбора», это «тщательные обсуждения и экспертиза», осмотрительность и осторожность в процессе выбора наиболее приемлемого и эффективного решения. ${ }^{2}$ Слово «Deliberation» очень часто переводится на русский язык как «взвешивание дискуссия $\sim$ медлительность; неторопливость». ${ }^{3}$

Предшественником нормативной модели делиберативной демократии можно считать Джона Дьюи, который предлагал трактовать демократию не столько как доминирование позиции большинства, но обращал внимание на механизмы достижения власти большинством. Он подчеркивал значение общественных дискуссий, дебатов и дискуссий в ходе которых «договари-

\footnotetext{
1 Burke B. Speech to the Electors of Bristol 3 Nov. 1774. Works vol. 1, p.446-448. URL: http://press-pubs. uchicago.edu/founders/documents/v1 ch13s7.html.

${ }^{2}$ Deliberation. URL: http://en.wiktionary.org/wiki/.

3 Перевод слова deliberation. URL: http://dic.your-english.ru/word/deliberation.
}

ваются» между собой разные социальные общности. Значительный вклад в их разработку и обоснование теории делиберативной демократии внесли Джозеф М. Бессет Джон Эльтер, Юрген Хабермас, Сейла Бенхабиб, Джемс Фишкин, Джошуа Коэн, Джон Ролз, Джон Драйцек, Деннис Томпсон, Робрт Б. Талиссе, Й.Коген, К.-П.Рипп и другие. В соответствии с эти, существуют различные подходы и определения делиберативной демократии и делиберативной политики. Так, к примеру, Дж. Фишкин, в качестве их фундамента рассматривает различные формы совещательных опросов. Раймер Шульце акцентрует внимание на их нормативном характере: «Делиберативная демократия - это нормативная демократическая модель, основывающаяся на доказательной силе систематических рассуждений и выводов в общественных дебатах, а также в коммуникативной, ориентированной на соглашение (договоренность) деятельность граждан». ${ }^{4}$ «Делиберативная демократия или делиберативная политика (англ. Deliberate - совместно обсуждать), -считает Д.В.Углов, -представляет собой такую модель общественного устройства, при которой формирование общественного мнения и политической воли в публичной сфере и парламенте страны подчиняется не структуре рыночных процессов или навязанной идеологии, но самобытной инициативе социальной коммуникации граждан, ориентированной на достижение взаимопонимания и защиту собственных интересов» $[4$, с. 232$] .^{5}$

Джон Драйзек, разрабатывая теорию делиберативной демократии, обращается прежде всего к критике либеральной трактовки демократии, считая данную модель формой простой агрегации (соединения) политических интересов. С его точки зрения, одной из фундаментальных проблем демократизации является вовлечение граждан в процесс управления. Как отмечает Д.Драйзек: «Демократизация, по большому счету, это вопрос возрастающего включения различных групп

\footnotetext{
${ }^{4}$ Schultze R. «Deliberative Demokratie»// Lexikon der Politikwissenshaft, Teorien, Methoden, Begriffe. Band I.A. - M, Munchen, 2002. P.119.

5 Углов Д. В. Тенденции делиберативной политики в теории справедливости Д. Ролза // Вестник ВГУ. Философия. 2009. №2. С.232.
} 
и категорий граждан в политическую жизнь». ${ }^{6}$ Как утверждает Дж.Драйзек, его анализ истории демократизации показал, что «требование большей демократии почти всегда возникают у оппозиционного гражданского общества, редко и почти никогда у государства». ${ }^{7}$ Поэтому Дж.Драйзек концентрирует внимание преимущественно на политических организациях гражданского общества (а не многочисленных свободных ассоциациях граждан), доказывая, что именно данные организации могут вносить наибольший вклад в обеспечение политического диалога (democratic deliberation) и укрепление демократических основ общества, прежде всего благодаря поддержанию их независимости от государства и способности стимулировать политическую дискуссию.

Данное обстоятельство предполагает необходимость соответствующей переориентации этих организаций, преодоления односторонности, связанной с выполнением функций поддержания политической власти и оказания влияния на результаты выборов. Из этой идеи Дж.Драйзек выводит аргументы в пользу обоснования роли гражданского общества «в продвижении транснациональной демократии с опорой на сеть подобных организаций, функционирующих по типу международных экологических организаций и политических структур подобного типа». ${ }^{8}$

С нашей точки зрения, делиберативный процесс хотя и отличен от политического дискурса, но очень близок к констуктивным формам общественного (публичного) диалога. На данное обстоятельство обращает внимание С. Бенхабиб. По мнению этой последовательницы Ю.Хабермаса, делиберативные процедуры и публичный диалог способствуют укреплению и легитимации политической власти. Демократию она определяет как «модель организации коллективного и публичного осуществления власти посредством основ-

\footnotetext{
${ }^{6}$ Dryzek $J$. Political Inclusion and the Dynamics of Democratization //The American Political Science Review. Vol.90. No.3 (Sep., 1996). P. 475.

7 Там же, p.476.

8 Лукин В.Н. Альтернативные модели демократии в политических системах глобального мира: концепция делиберативной демократии Д.Драйзека. URL: http://ms-solutions.ru/ index.php?option $=$ com_content $\&$ view $=$ article \& catid $=38: 2010$ 01-15-12-09-51\&id=142:2010-01-18-11-19-36\&Itemid=206.
}

ных институтов общества на основе соблюдения принципа, что решения, затрагивающие благосостояние общества, следует рассматривать как результат процедуры незатратного и обоснованного обсуждения среди морально и политически равных лиц». ${ }^{9}$

По Бенхабиб, совещательная модель демократии предполагает, то процесс принятия решений требует свободного и разумного публичного торга и процедуры общественного обсуждения среди всех социальных субъектов. С. Бенхабиб полагает, что это приведет к увеличению легитимности как политического режима, так и принимаемых решений, поскольку они проистекают из свободных дискуссий между конкурирующими группами. Для реализации принципов делиберативной демократии, все участники публичного диалога должны иметь одинаковые возможности участвовать в этом процессе, который регулируется нормами равенства и симметрии. Вовторых, все люди имеют «право на сомнение заданную тему разговора». В-третьих, все «имеют право инициировать рефлексивные рассуждения о самих правилах дискурса, порядках и способах, которые применяются или осуществляются» $[8, \mathrm{p} .70] .{ }^{10}$ С.Бенхабиб также подчеркивает, что в таких вопросах, как экологические проблемы процесс переговоров не должен быть ограничены членами нации-государства, а должен включать люди из разных стран, которые будут затронуты этим решение. Она признает, что при построении своей модели демократии, она была вдохновлена другими теориями. И не только Ю.Хабермасом, но, также теорией политического действия Ханны Арендт, модель сильной демократии Бенджамина Барбера, а таже различными пост-структуральными теориями, разработанными Уильям Коннолли, Шанталь Муфф и Эрнесто Лакло.

С точки зрения С.Бенхабиб, существует несколько причин для обсуждения наилучшей модели демократического устройства. Во-первых, ни

\footnotetext{
9 Benhabib S. «Toward a Deliberative Model of Democratic Legitimacy», in Seyla Benhabib (ed.),Democracy and Difference, Princeton, 1996. P. 68.

${ }^{10}$ Benhabib S. «Toward a Deliberative Model of Democratic Legitimacy», in Seyla Benhabib (ed.),Democracy and Difference, Princeton, 1996. P.70.
} 


\section{Политика и общество 10 (106) • 2013}

один человек или группа не может «предвидеть все разнообразие точек зрения по вопросам этики и политики, которые будут восприниматься разными людьми». ${ }^{11}$ Во-вторых, ни один человек или группа не может обладать всей полнотой информации, необходимой для того, чтобы сделать наиболее удачный рациональный выбор. Она также считает, что делиберативная модель демократии является процедуралистской, поскольку опирается на «определенные институциональные процедуры и практики для достижения решения по вопросам, которые были бы обязательными всех». ${ }^{12}$ При этом она считает, что в обществе обязательно должен сохраниться плюрализм с помощью которого можно избежать возникновения единого политического, морального или религиозного кода социума. Ведь в делиберативной демократии конфликтующие интересы, конкуренция и взаимное сотрудничество, взаимодействие, поиск консенсуса и компромисса играют весьма важную роль. Кроме того, данная модель демократии и политики сохраняет множество иных способов объединения граждан, принимая во внимание все типы существующих групп социума, в том числе политические партии, общественные движения, добровольные организации и организации гражданского общества и т.д.

Полемизируя с либералом Брюсом Аккерманом $^{13}$ по поводу понимания существа публичного диалога, С.Бенхабиб отмечает, что ее оппонент «понимает либерализм как способ обсуждения власти, как политическую культуру общественного диалога, основанного на определенных видах разговорных ограничений (условий, требований)». ${ }^{14}$ Наиболее значительное дискурсивное ограничение в либерализме - это объективность (беспристрастность, нейтралитет). Либеральная модель демократии рассматривает политические отношения слишком узко, сво-

\footnotetext{
11 Там же, p.71.
}

12 Там же, p.73.

${ }^{13}$ Ackerman B. Whi Dialogue? (1989). Faculty Scholarship Series. Paper 142.URL: http://digitalcommons.law.yale. edu/fss_papers/142.

${ }^{14}$ Benhabib S. «Models of Public Space: Hanna Arendt, the Liberal Tradition, and Jurgen Habermas»// Craig J.Calhoun. Habermas and the Public Space. -Cambridge, Mass: MIT Press, 1992. P.81. дя их к чисто юридическим проблемам и процедурам, в которых главным принципом выступает нейтральность в рассмотрении любых вопросов.

С точки зрения либерализма, для обеспечения эффективного функционирования публичной сферы необходимо, чтобы публичный диалог строился на принципе нейтральности аргументов, на речевой сдержанности, то есть, фактически, на беспристрастности. Сторонники либерализма настаивают на «процедурном критерии практического дискурса» ${ }^{15}$, суть которого состоит в том, что «протекание политического диалога можно заключить в довольно жесткие рамки», в то время как делиберативный, то есть «коммуникативный подход отказывается от таких притязаний» ${ }^{16}$.

Согласно модели либерального диалога, публичное пространство должно быть нейтральным. Брюс Акерман указывает, что публичный диалог должен быть «разумным способом» коммуникации, обладая «разговорной сдержанностью» в целях обеспечения сосуществования различных групп. ${ }^{17}$ Поэтому С.Бенхабиб называет либеральный подход к общественному диалогу «юридический» моделью публичной сферы.

С.Бенхабиб полагает, что для разрешения наиболее острых политических вопросов нельзя вводить процедурные ограничения в виде допустимых моделей аргументации. С ее точки зрения, «либеральная модель публичного пространства превращает политический диалог... в юридический дискурсе о праве». ${ }^{18}$ По мнению С.Бенхабиб и других представителей теории делиберативной демократии, «либералы не учитывают, что либеральные нормы диалога могут использоваться в том числе и для подавления альтернативных точек зрения в реальной политике». ${ }^{19}$ Она утверждает, что «либеральный принцип диалогического нейтралитета, выражая один из главных принципов

\footnotetext{
15 Шкурихин И.А. Демократизация парламентских институтов: коммуникативный и процедурный подходы// Вестник Томского государственного университета. 2011, №3 (15). C.104.

16 Там же, с.103.

17 Benhabib S. «Toward a Deliberative Model of Democratic Legitimacy», in Seyla Benhabib (ed.),Democracy and Difference, Princeton, 1996. P.96.

18 Там же, p. 94.

${ }_{19}$ Там же, р. 103-104.
} 
современной правовой системы, является ограничительным и тормозящим в применении к динамике борьбы за власть в реальных политических процессах». ${ }^{20}$ Дело в том, что классический либерализм утверждает, что предварительно, то есть еще до начала коммуникации, должны быть установлены правила диалога и его нормативные ограничения, в то время как С.Бенхабиб считает, что сами эти правила ведения дискуруса в ходе его осуществления могут стать предметом дискуссии. Она выступает против так называемого либерального «метода избегания», который ограничивает политический диалог в плюралистических обществах при рассмотрении остро дискуссионных и спорных вопросов. Согласно ее модели делиберативной демократии, публичная политика - это место свободной дискуссии и общественного диалога, способствующих принятию делиберативно обоснованных и коммуникативно легитимизированных политических дешений.

В целом можно сказать, что делиберативная политика и делиберативная демократия представляют собой «особый общественно-политический курс, ориентированный на рациональное обсуждение общественных проблем», который выдвигает «по отношению к институтам власти требование, чтобы все политические решения были опосредованы и легитимизированы таким обсуждением. - Считает А.В.Назарчук. - Содержание делиберативной политики составляет реализация принципа публичности в политической сфере». ${ }^{21}$ В современной России в сфере публичной политики появляются отдельные элементы делиберативной демократии и делиберативной политики как различные формы институционального диалога власти и гражданского общества (публичные слушания, гражданский контроль, общественные экспертизы, институт обращения граждан, гражданские инициативы, интерактивные телепередачи с участием представителей власти, работа общественных палат и обществен-

${ }^{20}$ Benhabib S. «Models of Public Space: Hanna Arendt, the Liberal Tradition, and Jurgen Habermas»// Craig J.Calhoun. Habermas and the Public Space. - Cambridge, Mass: MIT Press, 1992. P. 84.

${ }^{21}$ Назарчук А.В. Понятие делиберативной политики в современном политическом процессе// Полис. 2011, № 5 . C. 101 . ных советов, открытое правительство, электронное государство, общественное телевидение и т.д.). Однако, законодательная база, позволяющая на прочной правовой основе закрепить все еще немногочисленные делиберативные практики в сфере публичной политики, запаздывает, отстает от императивных требований времени. Так, к примеру, такие базовые законы, как ФЗ «Об общественной экспертизе нормативных правовых актов и проектов нормативных актов», Ф3 «Об общественном контроле в Российской Федерации» и др. остаются непринятыми, а элементы делиберативной политики и делиберативной демократии не институционализированы в рамках доминирующей, но устаревшей и неэффективной модели либерально-электоральной демократии.

Делиберацию, то есть совещания, переговоры, дискурсы, диалоги людей с целью нахождения взаимопонимания, консенсуса, компромиссов, заключения соглашений и договоров, можно рассматривать в качестве инструмента для разрешения даже самых острых социально-политических конфликтов. К такому способу приходят даже склонные к насилию социальные акторы, поскольку затраты на войну могут быть дороже стоимости вопроса по установлению конструктивного диалога. При этом следует понимать, что в любом обществе делиберативные практики разрешения конфликтов конкурируют с насильственными. И чем выше делиберативная культура социума, тем ниже уровень насилия, и обратно. Данное обстоятельство вполне приложимо к анализу ситуации в России, где делиберативная теория и практика пока что находятся на достаточно низком уровне своего развития. Оборотной стороной этого обстоятельства являются эскалация межнациональных конфликтов, насилия и террористических актов. Попытки решить эти проблемы административными, силовыми и или манипулятивными методами, без опоры на принципы делиберативной демократии и гражданский диалог лишь усугубляют общественнополитическую ситуацию и обречены на провал.

\section{Библиография:}

1. Лукин В.Н. Альтернативные модели демократии в политических системах гло- 


\section{Политика и общество 10 (106) • 2013}

бального мира: концепция делиберативной демократии Д. Драйзека. URL: http://mssolutions.ru/index.php?option $=$ com_content $\&$ view $=$ article\&catid=38:2010-01-15-12-0951\&id=142:2010-01-18-11-19-36\&Itemid=206.

2. Назарчук А.В. Понятие делиберативной политики в современном политическом процессе// Полис, 2011, № 5.

3. Перевод слова deliberation. URL: http://dic. your-english.ru/word/deliberation.

4. Углов Д. В. Тенденции делиберативной политики в теории справедливости Д. Ролза // Вестник ВГУ. Философия. 2009. №2.

5. Шкурихин И.А. Демократизация парламентских институтов: коммуникативный и процедурный подходы//Вестник Томского государственного университета. 2011, №3 (15).

6. Ackerman B Whi Dialogue? (1989). Faculty Scholarship Series. Paper 142.URL: http://digitalcommons.law.yale.edu/fss_papers/142.

7. Dryzek J. Political Inclusion and the Dynamics of Democratization //The American Political Science Review, Vol.90, No.3 (Sep., 1996).

8. Benhabib S, «Toward a Deliberative Model of Democratic Legitimacy», in Seyla Benhabib (ed.),Democracy and Difference, Princeton, 1996.

9. Benhabib S «Models of Public Space: Hanna Arendt, the Liberal Tradition, and Jurgen Habermas»// Craig J.Calhoun. Habermas and the Public Space. -Cambridge, Mass: MIT Press, 1992.

10. Burke B. Speech to the Electors of Bristol 3 Nov. 1774. Works vol. 1, p.446-448. URL: http://press-pubs.uchicago.edu/founders/documents/v1ch13s7.html.

11. Deliberation. URL: http://en.wiktionary.org/ wiki/.

12. Schultze R. «Deliberative Demokratie»// Lexikon der Politikwissenshaft, Teorien, Methoden, Begriffe. Band I.A. - M, Munchen, 2002.

\section{References (transliteration):}

1. Lukin V.N. Al'ternativnye modeli demokratii v politicheskikh sistemakh global'nogo mira: kontseptsiya deliberativnoi demokratii D.Draizeka. URL: http://ms-solutions.ru/index. php?option $=$ com_content $\&$ view $=$ article\&cat $\mathrm{id}=38: 2010-01-15-12-09-51 \& \mathrm{id}=142: 2010-01$ 18-11-19-36\&Itemid=206.

2. Nazarchuk A.V. Ponyatie deliberativnoi politiki v sovremennom politicheskom protsesse// Polis, 2011, № 5.

3. Uglov D. V. Tendentsii deliberativnoi politiki v teorii spravedlivosti D. Rolza // Vestnik VGU. Filosofiya. 2009. №2.

4. Shkurikhin I.A. Demokratizatsiya parlaments kikh institutov: kommunikativnyi i protsedurnyi podkhody//Vestnik Tomskogo gosudarstvennogo universiteta. 2011, №3 (15).

5. Ackerman V Whi Dialogue? (1989). Faculty Scholarship Series. Paper 142.URL: http://digitalcommons.law.yale.edu/fss_papers/142.

6. Dryzek J. Political Inclusion and the Dynamics of Democratization //The American Political Science Review, Vol.90, No.3 (Sep., 1996).

7. Benhabib S, «Toward a Deliberative Model of Democratic Legitimacy», in Seyla Benhabib (ed.),Democracy and Difference, Princeton, 1996.

8. Benhabib S «Models of Public Space: Hanna Arendt, the Liberal Tradition, and Jurgen Habermas»// Craig J.Calhoun. Habermas and the Public Space. -Cambridge, Mass: MIT Press, 1992.

9. Burke V. Speech to the Electors of Bristol 3 Nov. 1774. Works vol. 1, r.446-448. URL: http://press-pubs.uchicago.edu/founders/documents/v1ch13s7.html.

10. Schultze R. «Deliberative Demokratie»// Lexikon der Politikwissenshaft, Teorien, Methoden, Begriffe. Band I.A. - M, Munchen, 2002. 